\title{
Isoniazid-resistant Mutants of Mycobacterium tuberculosis H 37 RV: Uptake of Isoniazid and the Properties of NADase Inhibitor
}

\author{
By K. S. SRIPRAKASH AND T. RAMAKRISHNAN \\ Microbiology and Pharmacology Laboratory, Indian Institute of Science, \\ Bangalore I2, India
}

(Accepted for publication 15 October 1969)

SUMMARY

Six independent isoniazid-resistant mutants of Mycobacterium tuberculosis were isolated under conditions which largely ensured the selection of onestep mutants. The properties of these mutants with respect to the nicotinamide adenine dinucleotide nucleosidase (NADase) inhibitor, isoniazid uptake and peroxidase activity were studied. The uptake of isoniazid by the mutants and their sensitivity to isoniazid were increased by ethylenediaminetetra-acetic acid (EDTA) and sodium dodecylsulphate. It is suggested that EDTA and sodium dodecylsulphate bring about these effects by altering the cell permeability.

\section{INTRODUCTION}

Isoniazid (INH) is specific in its inhibitory action on the growth of mycobacteria; its mechanism of action on this group of organisms has been examined by many workers. Gopinathan et al. (1963, 1964, 1966) showed the presence of a heat-labile inhibitor of nicotinamide adenine dinucleotide nucleosidase (NADase) in Mycobacterium tuberculosis $\mathrm{H} 37 \mathrm{RV}$ and purified the enzyme and the inhibitor. Bekierkunst (I966) noticed that INH, which had no effect on mycobacterial NADase (Gopinathan et al. I964), caused a decrease in the NAD content of the organism and suggested that the drug might inactivate the inhibitor, thereby enhancing the activity of NADase. Sriprakash \& Ramakrishnan (1966) confirmed that INH in vitro interacted with NADase-inhibitor complex and thereby enhanced the activity of NADase. It can be argued on the basis of these findings that if the primary mechanism of action of INH is through the inactivation of the inhibitor of NADase, then the inhibitor from INHresistant mutants might have lost its sensitivity to INH. The results presented in this paper show that resistance to INH is accompanied by an alteration in the permeability of the organism to the drug, while only in a few of these mutants the inhibitor also lost the sensitivity to INH. It is also shown that in both types of mutants, the organism is sensitized to INH by treating it with ethylenediaminetetra-acetic acid (EDTA) or sodium dodecylsulphate. A preliminary communication has been published (Sriprakash \& Ramakrishnan, I968).

\section{METHODS}

Chemicals. NAD was obtained from Sigma Chemical Co., St. Louis, U.S.A.; INH from Dumex (India) Private Ltd. Bombay; EDTA from E. Merck, Darmstadt, Germany; phenylethylalcohol from Distillation Products Industries, Rochester, U.S.A.; labelled $7-\left[{ }^{14} \mathrm{C}\right] \mathrm{INH}$ (Io $\mathrm{mc} . / \mathrm{m}$-mole) was purchased from the Radiochemical Centre, Buckinghamshire, England. Other reagents were of Analar grade. 
Organisms. Mycobacterium tuberculosis $\mathbf{H} 37 \mathrm{RV}$, originally obtained from National Collection of Type Cultures, London (NCTC 74I6) and maintained on Petrik medium, was used in the present studies. To obtain inocula for growth experiments Sauton liquid medium was used. For enzyme studies the organism was grown in the liquid medium of Youmans \& Karlson (I947) with glycerol as carbon source and asparagine as nitrogen source. All incubations were at $37^{\circ}$.

Preparation of cell-free extracts. This was done by ultrasonic treatment as described by Murthy, Sirsi \& Ramakrishnan (1962).

Enzyme assays. NADase activity was measured by the cyanide addition method (Zatman, Kaplan \& Colowick, I953). The purification and assay of NADase inhibitor were described by Gopinathan, Ramakrishnan \& Vaidyanathan (I966). One unit of NADase is defined as that amount of enzyme which breaks down I nmole NAD $/ \mathrm{min}$. at $37^{\circ}$ under the conditions of assay. One unit of NADase inhibitor is defined as that amount of inhibitor which inhibits I unit of enzyme by $50 \%$ at $37^{\circ}$.

Peroxidase assay was done as follows. One $\mathrm{ml}$. of the reaction mixture contained potassium phosphate buffer ( $\mathrm{pH} 7.0$ ) IOO $\mu$ mole; hydrogen peroxide $0.1 \mu$ mole; pyrogallol, $5 \mu \mathrm{mole}$; and enzyme. The reaction was stopped after $10 \mathrm{~min}$. with $3 \mathrm{ml}$.

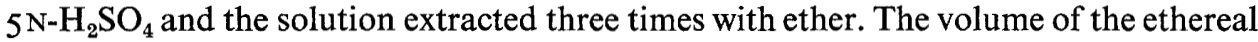
extract was made to $5.0 \mathrm{ml}$. with ethanol $(95 \%, \mathrm{v} / \mathrm{v}$ in water $)$ and the colour measured in a Klett-Summerson Colorimeter with filter no. 42.

Other assays. Total oxidized pyridine nucleotides were estimated by the ethylmethylketone method of Carpenter \& Kodicek (1950) by using a Carl Zeiss Spekol Fluorimeter. Radioactive measurements of the bacteria were done by drying them on tared aluminium planchets and counting in a gas-flow proportional counter. Other radioactivity measurements were made with a Beckman liquid scintillation counter, Model LS-IOO.

Isolation of INH-resistant mutants. Six tubes each containing I ml. Sauton medium were inoculated with about $10^{3}$ Mycobacterium tuberculosis $\mathrm{H} 37 \mathrm{RV}$ organisms and incubated till the colony count was $10^{7}$. Samples $(0.1 \mathrm{ml}$.) from each of the tubes were streaked on to Petrik medium containing $0 . \mathrm{I} \mu \mathrm{g}$. INH/ml. and incubated till the growth was visible. The isolated colonies were subcultured and maintained on Youmans \& Karlson medium containing the same concentration of INH.

\section{RESULTS}

INH-resistant mutants. Six independent INH-resistant mutants were isolated. They were all found to be resistant to $\mathrm{I} \cdot 0 \mu \mathrm{g}$. INH/ml., when tested in Youmans medium, in spite of their selection of INH resistance at $0 . \mathrm{I} \mu \mathrm{g} . / \mathrm{ml}$. All these mutants were inhibited by INH at $\mathrm{r} \cdot 5 \mu \mathrm{g} . / \mathrm{ml}$. and above. These mutants are referred to as inh-r-I, inh-r-2, inh-r-3, inh-r-4, inh-r5, inh-r-6.

The effect of INH on NAD concentrations. The results presented in Table I indicate that in the INH-resistant strains INH did not cause the depletion of NAD, up to I $\mu \mathrm{g}$. INH/ml., to which concentration these bacilli were resistant. On the other hand, in the wild type NAD was decreased to the extent of $50 \%$ with $0 . \mathrm{I} \mu \mathrm{g}$. INH/ml. These results are consistent with those reported by Bekierkunst \& Bricker (1967) for Mycobacterium tuberculosis $\mathrm{H} 37$, Ra.

Effect of INH on NADase. NADase was purified from Mycobacterium tuberculosis $\mathrm{H} 37 \mathrm{RV}$ and the mutants inh-r-4 and inh-r-6, and the effect of INH was studied on the 
enzyme. INH had no direct activating effect on NADase of wild type or on either type of INH-resistant bacilli (Table 2).

\section{Table I. Effect of INH on NAD concentration in sensitive and resistant tubercle bacilli} Different concentrations of INH were aseptically added to a 15 -day culture which was then
further incubated for $24 \mathrm{hr}$. The bacilli were harvested, washed with cold water, suspended in
cold $5 \%$ trichloracetic acid and treated ultrasonically for $5 \mathrm{~min}$. at 0 to 3 in $10 \mathrm{kc}$. Raytheon
Sonic Oscillator. The suspensions were then centrifuged at $13,000 \mathrm{~g}$ in cold for 30 min. and
the supernatant fluid after neutralization with $\mathrm{N}-\mathrm{NaOH}$ was used for determination of NAD.

\begin{tabular}{|c|c|c|}
\hline Culture & $\begin{array}{c}\text { INH } \\
(\mu \mathrm{g} . / \mathrm{ml} .)\end{array}$ & $\begin{array}{l}\mu \mathrm{g} . \text { NAD } \\
\text { wet bact }\end{array}$ \\
\hline \multirow[t]{3}{*}{ M. tuberculosis H $37 \mathrm{RV}$} & 0 & 220 \\
\hline & $0 \cdot I$ & 115 \\
\hline & 0.5 & \\
\hline \multirow[t]{5}{*}{ Mutant inh-r-4 } & 0 & 220 \\
\hline & $0 \cdot I$ & $23 I$ \\
\hline & 0.5 & 217 \\
\hline & $I \cdot O$ & 222 \\
\hline & $1 \cdot 5$ & 132 \\
\hline \multirow[t]{5}{*}{ Mutant inh-r-6 } & 0 & 175 \\
\hline & 0.1 & 177 \\
\hline & 0.5 & I 68 \\
\hline & $I \cdot O$ & 170 \\
\hline & $\mathrm{I} \cdot 5$ & 122 \\
\hline
\end{tabular}

Table 2. Effect of INH on NADase

The reaction mixture contained $100 \mu$ mole potassium phosphate buffer (pH 6.7); NAD, $0.2 \mu$ mole; enzyme, I unit; total volume $0.6 \mathrm{ml}$. The mixture was incubated for $1 \mathrm{hr}$. INH $1 \cdot 0 \mu$ mole was included in the reaction mixture.

\begin{tabular}{|c|c|c|}
\hline Cultures & $\begin{array}{c}\text { NADase activity } \\
\text { No INH }\end{array}$ & $\begin{array}{c}\text { (Extinction } / \mathrm{hr} / \\
\text { unit enzyme) } \\
\text { INH I } 7 \mu \text { mole } / \mathrm{ml} \text {. }\end{array}$ \\
\hline M. tuberculosis H $37 \mathrm{RV}$ & 0.105 & 0.106 \\
\hline inh-r-4 & 0.105 & $0 \cdot 103$ \\
\hline inh-r-6 & $0 \cdot 105$ & $0 \cdot I O I$ \\
\hline
\end{tabular}

Effect of INH on NADase-inhibitor complex. It can be seen (Fig. I) that the organisms were of two types. The wild type and the mutants inh-r-1, inh-r-3, inh-r-4 and inh-r-5 belonged to the first type, where the inhibitor was sensitive to INH. The mutants inh-r-2 and inh-r-6 belonged to the second type, where the inhibitor was not sensitive to INH. The effect of INH on NADase-inhibitor heterocomplexes was studied to find whether the change had occurred in the inhibitor or the enzyme in mutants inh-r-2 and inh-r-6.The heterocomplexes were obtained by mixing purified NADase of one strain with the purified inhibitor of a different strain. The results (Table 3 ) indicated that INH annulment of inhibitor activity was not observed with the heterocomplexes which were composed of the inhibitor of mutant inh-r-2 or inh-r-6. It was therefore concluded that the inhibitor of these two strains alone was altered.

To investigate whether the alteration of the inhibitors of inh-r-2 and inh-r-6 resulted in their inability to bind INH, equilibrium dialysis was done with these inhibitors and 
labelled INH. Mutants inh-r-4 and inh-r-6 were chosen as the representatives of two types of mutants. The results (Table 4 ) showed that the binding of INH by the inhibitor of $i n h-r-6$ was insignificant as compared to that by the inhibitors of $i n h-r-4$ and wild-type organisms.

Peroxidase activity of Mycobacterium tuberculosis. While the wild type was peroxidasepositive all the mutants were peroxidase-negative. To find whether peroxidase and the NADase inhibitor were one and the same protein the inhibitor was purified up to the alumina $\mathrm{C} \gamma$-gel elution stage and both activities were determined at every stage. The ratio of peroxidase activity to the inhibitor activity was almost constant up to the alumina $\mathrm{C} \gamma$-gel elution stage of purification (Table 5).

\section{INH uptake by Mycobacterium tuberculosis}

Since a change in the sensitivity of NADase inhibitor to INH could explain the resistance to INH of only two of six resistant strains, the uptake of INH by these

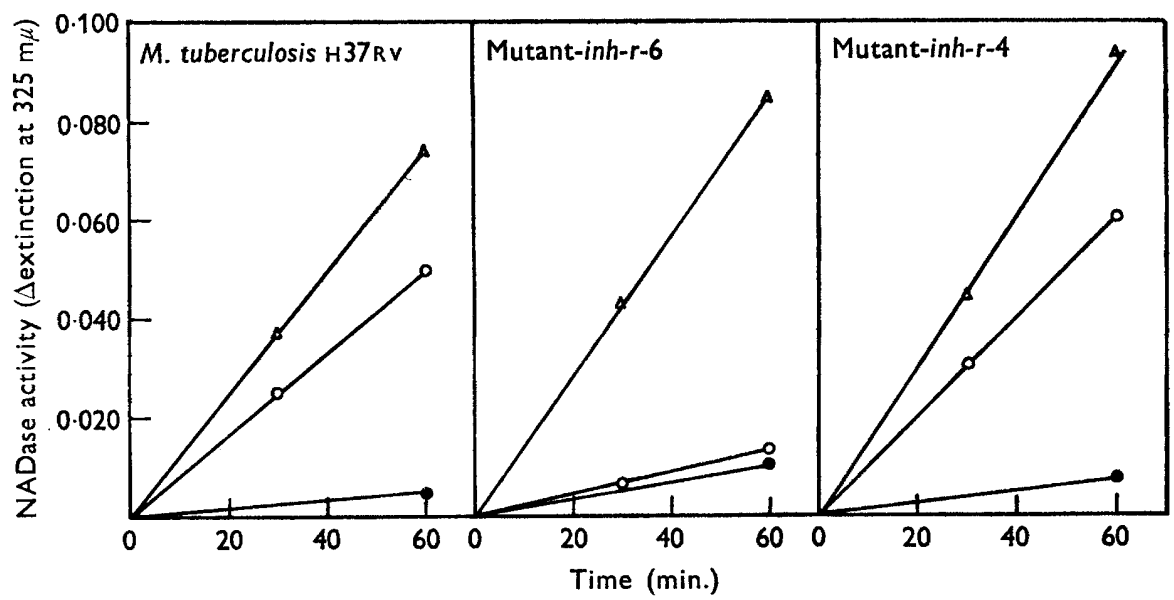

Fig. I. The effect of INH on NADase-inhibitor complex. Incubation mixture ( $0.6 \mathrm{ml}$.) contained $100 \mu$ mole phosphate buffer ( $\mathrm{pH} \mathrm{6.7)}$, with or without I $\mu$ mole INH and crude cellfree extract. The reaction mixture was incubated for $20 \mathrm{~min}$. at $37^{\circ}$. NAD $(0.25 \mu$ mole) was added and further incubated for $\mathrm{I} \mathrm{hr}$. The total NADase activity was determined by heating the cell-free extract at $80^{\circ}$ for $1 \mathrm{~min}$. before adding NAD. Incubation temperature $37^{\circ} . \triangle$, NADase activity of heat-treated cell-free extract; $O$, NADase activity of INH-treated cellfree extract; $O$, NADase activity of cell-free extract.

\section{Table 3. Effect of INH on the heterocomplexes}

Purified NADase and inhibitor from different sources were mixed and incubated for $15 \mathrm{~min}$. at $37^{\circ}$. The effect of INH on the heterocomplex was studied by further incubation of this mixture with $\mathrm{I} \cdot 0 \mu \mathrm{mole} \mathrm{INH}$ for $20 \mathrm{~min}$. at $37^{\circ}$ and the NADase activity assayed.

\begin{tabular}{|c|c|c|c|c|c|}
\hline \multirow[b]{2}{*}{ Source of NADase } & \multicolumn{5}{|c|}{ Source of the inhibitor } \\
\hline & H 37 RV & inh-r-I & inh-r-2 & inh-r-4 & $i n h-r-6$ \\
\hline H $37 \mathrm{RV}$ & + & + & - & + & - \\
\hline$i n h-r-1$ & + & + & - & + & - \\
\hline$i n h-r-2$ & + & + & - & + & - \\
\hline$i n h-r-4$ & + & + & - & + & - \\
\hline$i n h-r-6$ & + & + & - & + & - \\
\hline
\end{tabular}

$+=$ Annulment of inhibitor activity; $-=$ no annulment of inhibitor activity. 
strains was examined. INH uptake was found to be decreased in all the mutants as compared with the wild type. The results with two of the mutants (inh-r-4, inh-r-6) are illustrated in Table 6. The effect of certain compounds which have been reported to alter cell permeability of other bacteria, on the uptake of INH was examined. These compounds were incorporated into the Youmans \& Karlson medium along with $\left[{ }^{14} \mathrm{C}\right] \mathrm{INH}$. The results (Table 6) showed that ethylenediaminetetra-acetate and sodium dodecylsulphate increased the uptake of both types of resistant mutants, while phenylethylalcohol inhibited this uptake. These effects were consistent when the experiments were repeated a number of times.

\section{Table 4. Equilibrium dialysis of NADase inhibitor}

The purified inhibitor was concentrated by lyophilization to about $500 \mu \mathrm{g}$. protein $/ \mathrm{ml}$. The concentrated inhibitor was dialysed against $0.05 \mathrm{M}$-potassium phosphate buffer $(\mathrm{pH} 7 \cdot 0)$ containing $0.0 \mathrm{I} \mu \mathrm{C} .7-\left[{ }^{14} \mathrm{C}\right] \mathrm{INH} / \mathrm{ml}$. for $24 \mathrm{hr}$ at 0 to $5^{\circ}$ by using Visking tubing, pretreated by boiling in $10^{-3} \mathrm{M}-E D T A$ thrice. The radioactivity inside and outside the Visking tubing was measured.

$\begin{array}{cccc}\begin{array}{c}\text { Source of } \\ \text { inhibitor }\end{array} & \begin{array}{c}\text { Counts } / \\ \text { min. }\end{array} & \begin{array}{c}\text { Protein } \\ \text { content }(\mu \mathrm{g} .)\end{array} & \begin{array}{c}{\left[{ }^{14} \mathrm{C}\right] \mathrm{INH}} \\ \text { bound } / \mathrm{mg} . \\ \text { inhibitor } \\ \text { protein }\end{array} \\ \begin{array}{c}\text { M. tuberculosis } \\ \text { H } 37 \mathrm{RV}\end{array} & 625 & 500 & 1250 \\ \text { inh-r-4 } & & & \\ \text { inh-r-6} & 725 & 550 & 1320 \\ & 180 & 580 & 310\end{array}$

* Represents the difference in counts between the outside and inside of the dialysis tubing.

Table 5. Ratio of inhibitor activity to peroxidase activity

\begin{tabular}{|c|c|c|c|}
\hline Stage of purification & $\begin{array}{c}\text { Units of } \\
\text { inhibitor/ } \\
\text { ml. }\end{array}$ & $\begin{array}{c}\text { Units of } \\
\text { peroxidase } / \\
\text { ml. }\end{array}$ & $\begin{array}{c}\text { Ratio of } \\
\text { inhibitor } \\
\text { activity to } \\
\text { peroxidase } \\
\text { activity }\end{array}$ \\
\hline DEAE-eluate & $36 \cdot 0$ & $2 \cdot 2$ & $16 \cdot 0$ \\
\hline DEAE-eluate dialysed & $32 \cdot 0$ & I.9 & $17 \cdot 0$ \\
\hline Alumina $\mathrm{C} \gamma$-gel eluate I & $27 \cdot 0$ & $\mathrm{I} \cdot 8$ & $15 \cdot 0$ \\
\hline Alumina $C \gamma$-gel eluate II & $44 \cdot 0$ & $2 \cdot 9$ & $15 \cdot 0$ \\
\hline Alumina $\mathrm{C} \gamma$ supernatant & $26 \cdot 5$ & $I \cdot 5$ & $18 \cdot 0$ \\
\hline
\end{tabular}

The effect of increased INH uptake on INH-resistant tubercle bacilli

Experiments were made to determine whether these compounds increased the bacteriostatic effect of INH. Various concentrations of these compounds and INH were incorporated into Youmans \& Karlson medium and inoculated with INH-resistant bacilli. The results are given in Table 7. EDTA at $5 \times 10^{-3} \mathrm{M}$ when included in the medium with INH $0.5 \mu \mathrm{g} . / \mathrm{ml}$. completely inhibited the growth of both types of resistant mutant. However, the concentration of EDTA used by itself slightly retarded growth. On the other hand, sodium dodecylsulphate at $0.0 \mathrm{I} \%+\mathrm{INH} 0.5 \mu \mathrm{g} . / \mathrm{ml}$. inhibited the growth of both kinds of INH-resistant mutant; sodium dodecylsulphate alone was not inhibitory. Phenylethylalcohol did not supplement the effect of INH on any of the INH-resistant mutants and was itself inhibitory to growth at $0.1 \%$. 
Table 6. The effect of ethylenediaminetetra-acetate, phenylethylalcohol and sodium dodecylsulphate on the uptake of INH by INH-sensitive and INH-resistant mycobacteria

The I5-day cultures were inoculated into Youmans \& Karlson medium containing $0.05 \mu \mathrm{C}$. $\mathrm{INH} / \mathrm{ml}$. and incubated for $40 \mathrm{hr}$. The organisms were then washed with Youmans \& Karlson medium containing $10 \mu \mathrm{g}$. unlabelled $\mathrm{INH} / \mathrm{ml}$, , and finally with distilled water.

\begin{tabular}{|c|c|c|c|c|c|c|}
\hline & \multicolumn{2}{|c|}{ M. tuberculosis H $37 \mathrm{RV}$} & \multicolumn{2}{|c|}{ Mutant $i n h-r-4$} & \multicolumn{2}{|c|}{ Mutant inh-r-6 } \\
\hline Treatment & $\begin{array}{l}\text { Counts*/ } \\
5 \mathrm{~min} . / \\
\text { Io mg. } \\
\text { dry wt }\end{array}$ & $\begin{array}{c}\text { Relative } \\
\% \text { of } \\
{\left[{ }^{14} \text { C]INH }\right.} \\
\text { uptake }\end{array}$ & $\begin{array}{c}\text { Counts*/ } \\
5 \mathrm{~min} . / \\
\text { Io mg. } \\
\text { dry wt }\end{array}$ & $\begin{array}{c}\text { Relative } \\
\% \text { of } \\
{\left[{ }^{14} \mathrm{C}\right]} \\
\text { uptake }\end{array}$ & $\begin{array}{l}\text { Counts*/ } \\
5 \mathrm{~min} . / \\
\text { Io mg. } \\
\text { dry wt }\end{array}$ & $\begin{array}{c}\text { Relative } \\
\% \text { of } \\
{\left[{ }^{14} \mathrm{C}\right]} \\
\text { uptake }\end{array}$ \\
\hline- & 420 & $100 \cdot 0$ & 70 & 17 & 140 & 33 \\
\hline $5 \times 10^{-3} \mathrm{M}-\mathrm{EDTA}$ & 360 & $85 \cdot 0$ & I Io & 26 & 220 & 52 \\
\hline $0.01 \%$ Sodium dodecylsulphate & 440 & $105^{\circ} 0$ & 120 & 29 & 230 & 55 \\
\hline $0.1 \%$ Phenylethylalcohol & 240 & $57 \cdot 0$ & 30 & 7 & 100 & 24 \\
\hline
\end{tabular}

* Represents the total counts from which the background (I Io counts/5 min.) counts have been subtracted.

Table 7. Effect of ethylenediaminetetra-acetate, sodium dodecylsulphate and phenylethylalcohol on the growth of Mycobacterium tuberculosis inh-r-6 in the presence of subinhibitory concentration of INH

The growth was measured by determining the dry weight of organisms after 15 days of incubation. The pattern for mutant inh-r-4 was essentially the same.

\begin{tabular}{|c|c|c|c|c|c|}
\hline \multirow[b]{2}{*}{ Compounds used } & \multirow[b]{2}{*}{ Concentration } & \multicolumn{4}{|c|}{ Concentration of INH $(\mu \mathrm{g} . / \mathrm{ml})}$. \\
\hline & & 0 & 0.1 & 0.5 & $I \cdot O$ \\
\hline & & \multicolumn{4}{|c|}{ Growth (mg. dry wt) } \\
\hline - & - & 16 & 17 & 17 & 16 \\
\hline \multirow{2}{*}{$\begin{array}{l}\text { Ethylenediamine- } \\
\text { tetra-acetate }\end{array}$} & $5 \times 10^{-3} \mathrm{M}$ & 15 & I0 & 0 & 0 \\
\hline & $10^{-2} \mathrm{M}$ & 9 & I I & 0 & 0 \\
\hline \multirow{2}{*}{$\begin{array}{l}\text { Sodium dodecyl- } \\
\text { sulphate }\end{array}$} & $0.005 \%$ & 16 & 15 & 17 & 17 \\
\hline & $0.01 \%$ & 17 & 17 & 12 & 0 \\
\hline \multirow{3}{*}{$\begin{array}{l}\text { Phenylethyl- } \\
\text { alcohol }\end{array}$} & $0.01 \%$ & 18 & 16 & 16 & 17 \\
\hline & $0.05 \%$ & 12 & 10 & I I & 9 \\
\hline & $0.1 \%$ & 0 & 0 & 0 & 0 \\
\hline
\end{tabular}

\section{DISCUSSION}

In this work the mechanism of INH resistance in Mycobacterium tuberculosis $\mathrm{H} 37 \mathrm{RV}$ has been investigated by using independent mutants of the organism selected under conditions that largely ensured the isolation of single-step mutants, by exposing the organism to low growth-inhibitory concentration of INH. Such single-step mutants, unlike resistant strains selected by exposure to graded concentrations of INH, may be expected to have a single biochemical alteration which is solely responsible for resistance. By the above procedure two types of INH-resistant strains were isolated, one in which the NADase inhibitor had lost its sensitivity to INH accompanied by decreased uptake of INH and a loss of peroxidase activity, while in the second type only the uptake of INH and the peroxidase activity werelost. Apparently both types are the results of mutations in the same locus, since the same method of isolation had been used and they were resistant to the same maximum dose of INH. Though the mutants were isolated on media containing $0 . \mathrm{I} \mu \mathrm{g} . \mathrm{INH} / \mathrm{ml}$. they were 
all resistant to a maximum concentration of $\mathrm{I} \cdot 0 \mu \mathrm{g}$. $\mathrm{INH} / \mathrm{ml}$. Evidence for one-step mutation being capable of causing the highest degree of resistance of $M$. tuberculosis to isoniazid was presented by Middlebrook (I957).

If a single mutational step is involved in producing strains which are altered in isoniazid uptake, in the NADase inhibitor and in peroxidase activity, this suggests that all these are functions of the same protein. In partial support of this we have shown that the NADase inhibitor and peroxidase activities go together when the protein is purified. The involvement of peroxidase in INH uptake was suggested by Wimpenny (1967). The existence of mutants altered only in two functions, namely, isoniazid uptake and peroxidase activity, indicates that this protein can be altered so as to change two of its functions, but not the third.

There appears to be direct correlation between the sensitivity of Mycobacterium tuberculosis to INH and the depletion of NAD in the organism in the presence of isoniazid. The mechanism of this relationship is not clear. The hypothesis of Bekierkunst (I966) that depletion of NAD is due to the indirect activation of NADase does not appear to be wholly valid since the effect of isoniazid on the NAD content of the resistant mutants is the same whether or not the NADase inhibitor is altered. Two other possible explanations for the difference in the depletion of NAD in the presence of INH between INH-sensitive and INH-resistant strains were disproved by appropriate experiments. INH at $\mathrm{I} \cdot 5 \mu \mathrm{mole} / \mathrm{ml}$. had no direct activating effect on the NADase of wild type or INH-resistant mutants of $M$. tuberculosis. On the other hand, INH has inhibitory action on NAD biosynthesis in the extracts of $M$. tuberculosis, but this inhibition is exerted to the same extent in INH-sensitive and INH-resistant strains (Sriprakash \& Ramakrishnan, 1969). The possibility that INH brings about the leakage of intracellular NAD is being investigated. However, a simple explanation of this difference may be that the decrease in NAD is a secondary consequence of other damage to the cell by INH, which would be expected to occur only in resistant strains at concentrations of INH higher than those to which these strains are resistant.

The results from the $\left[{ }^{14} \mathrm{C}\right] \mathrm{INH}$ experiments show that alteration in permeability to INH is a major factor in the resistance of Mycobacterium tuberculosis to this drug. Evidence of the decreased uptake of INH by resistant tubercle bacilli has been given by many workers (Barclay, Ebert \& Koch-weser, 1953; Barclay, Koch-weser \& Ebert 1954; Boone, Strang \& Rogers, I957; Youatt, I958, I960a, $b$; Wimpenny, 1967). It was observed in the present work that compounds such as ethylenediaminetetraacetate and sodium dodecylsulphate which have been shown to act on membranes of other bacteria (Lieve, I965; Bayer \& Anderson, 1965) increased the uptake of INH by the resistant organism. Phenylethylalcohol, another membrane-active agent (Silver \& Wendt, 1967), on the other hand, had no such effect. Once INH had accumulated in the resistant organisms, it exerted its bacteriostatic effect irrespective of whether or not the NADase inhibitor was sensitive to INH. This appears to confirm the conclusion that in the mechanism of INH resistance, permeability plays a more important role than the sensitivity of the inhibitor to INH. The emergence of resistance to isoniazid by $M$. tuberculosis appears to be more frequent than that to streptomycin, which has been reported to be $\mathrm{IO}^{-9}$ (Szybalski \& Bryson, 1952). The frequency of resistance to isoniazid is reported by the above authors to be ( 1 to 3 ) $\times 10^{-6}$ by using the statistical method of Delbruck \& Luria.

The authors thank Professor M. Sirsi for his interest in the work, the University 
Grants Commission, New Delhi, for the award of a Senior Fellowship to one of them (K. S. S.) and to Professor A. N. Radhakrishnan, Wellcome Research Unit, Christian Medical College, Vellore, for assistance in measuring radioactivity with the liquid scintillation counter in his unit.

\section{REFERENCES}

Barclay, W. R., Ebert, R. H. \& Koch-Weser, D. (1953). Mode of action of isoniazid. American Review of Tuberculosis and Pulmonary Diseases 67, 490.

Barclay, W. R., Koch-Weser, D. \& Ebert, R. H. (1954). Mode of action of isoniazid. II. American Review of Tuberculosis and Pulmonary Diseases 7o, 784.

BAyer, M. E. \& Anderson, T. F. (1965). The surface structure of Escherichia coli. Proceedings of the National Academy of Sciences of the United States of America 54, I592.

BekIERKUNST, A. (1966). Nicotinamide adenine dinucleotide in tubercle bacilli exposed to isoniazid. Science, New York 152, 525.

BeKIERKunSt, A. \& BRICKER, A. (1967). Studies on the mode of action of isoniazid on mycobacteria. Archives of Biochemistry and Biophysics 122, 385 .

Boone, I. U., Strang, V. G. \& Rogers, B. S. (I957). Effect of pyridoxal on uptake of ${ }^{14} \mathrm{C}$-activity from labelled isoniazid by Mycobacterium tuberculosis. American Review of Tuberculosis and Pulmonary Diseases 76, 568.

CARPENTER, L. J. \& KodICEK, E. (1950). The fluorimetric estimation of $N^{\prime}$-methylnicotinamide and its differentiation from coenzyme I. Biochemical Journal 46, $42 \mathrm{I}$.

Gopinathan, K. P., Ramakrishnan, T. \& Vaidyanathan, C. S. (I966). Purification and properties of an inhibitor for nicotinamide adenine dinucleotidase from Mycobacterium tuberculosis H 37 RV. Archives of Biochemistry and Biophysics r13, 367.

Gopinathan, K. P., Sirsi, M. \& Ramarkishnan, T. (I963). Nicotinamide adenine nucleotides of Mycobacterium tuberculosis $\mathrm{H} 37 \mathrm{RV}$. Biochemical Journal 87, 444.

Gopinathan, K. P., Sirsi, M. \& Vaidyanathan, C. S. (1964). Nicotinamide adenine dinucleotide glycohydrolase from Mycobacterium tuberculosis H 37 RV. Biochemical Journal 9r, 277.

LIEVE, L. (I965). Actinomycin sensitivity in Escherichia coli produced by EDTA. Biochemical and Biophysical Research Communications 18, 13.

MidDLEBRooK, G. (I957). Diagnostic and biological problems of isoniazid-resistant tubercle bacilli. Proceedings of the Fourteenth International Tuberculosis Conference, New Delhi, p. 7I.

Murthy, P. S., Sirsi, M. \& Ramakrishnan, T. (1962). Tricarboxylic acid cycle and related enzymes in cell-free extracts of M. tuberculosis H 37 RV. Biochemical Journal 84, 263.

SILVER, S. \& WENDT, L. (1967). Mechanism of action of phenethyl alcohol: breakdown of the cellular permeability barrier. Journal of Bacteriology 93, 560.

SRPIRAKASH, K. S. \& RamaKRishnan, T. (1966). Comparative study of nicotinamide adenine dinucleotide nucleosidase from Mycobacterium tuberculosis $\mathrm{H} 37 \mathrm{RV}$ and pig brain: effect of isonicotinic acid hydrazide on the enzyme inhibitor complex. Indian Journal of Biochemistry 3,21 I.

SRIPRAKash, K. S. \& Ramakrishnan, T. (1968). Studies on the mechanism of isoniazid resistance in Mycobacterium tuberculosis $\mathrm{H} 37$ Rv. Indian Journal of Biochemistry 5, 185.

SRIPRAKASH, K. S. \& RAMAKRISHNAN, T. (1969). Isoniazid and nicotinamide adenine dinucleotide synthesis in Mycobacterium tuberculosis. Indian Journal of Biochemistry 6, 49.

SZYBALSKI, W. \& BRYSON, V. (I952). Bacterial resistance studies with derivatives of isonicotinic acid. American Review of Tuberculosis and Pulmonary Diseases 65, 768.

WimpENNy, J. W. T. (1967). The uptake and fate of isoniazide in Mycobacterium tuberculosis var. bovis BCG. Journal of General Microbiology 47, 389 .

YouatT, J. (1958). The uptake of isoniazid by washed cell suspensions of Mycobacteria and other organisms. Australian Journal of Experimental Biology and Medical Sciences 36, 223.

YouATT, J. (1960a). The metabolism of isoniazid and other hydrazides by Mycobacteria. Australian Journal of Experimental Biology and Medical Sciences 38, 245.

Youatr, J. $(1960 \mathrm{~b})$. The uptake of isoniazid and related compounds by Mycobacteria. Australian Journal of Experimental Biology and Medical Sciences 38, 33I.

Youmans, G. P. \& KarLSON, A. G. (I947). Streptomycin sensitivity of tubercle bacilli; studies on recently isolated tubercle bacilli and the development of resistance to streptomycin in vivo American Review of Tuberculosis and Pulmonary Diseases 55, 529.

Zatman, L. J., Kaplan, O. \& Colowick, S. P. (1953). Inhibition of spleen diphosphopyridine nucleotidase by nicotinamide, an exchange reaction. Journal of Biological Chemistry 200, 197.

\section{Note added in proof}

The first step INH-resistant mutants were all found to be resistant to $4.0 \mu \mathrm{g} \mathrm{INH} / \mathrm{ml}$. when tested on Petrik medium, though in Youman's medium they were resistant only to $\mathrm{I} \cdot 0 \mathrm{~g} \mathrm{INH} / \mathrm{m} 1$. 